\title{
OS DESAFIOS DO COMBATE ̀̀ VIOLÊNCIA CONTRA A MULHER SOB A ÓTICA DE PIERRE BOURDIEU
}

\author{
BRENDA ALICE ANDRADE VIDIGAL
}

Bacharel em Enfermagem pela Universidade do Estado do Amazonas. Mestranda pelo Programa de pós-graduação do Departamento de Enfermagem Psiquiátrica e Ciências Humanas da Escola de Enfermagem de Ribeirão Preto da USP.

\section{MARCOS PRATA BENTES}

Bacharel em Direito pela Universidade Federal do Amazonas (UFAM). Especialista em Direito Penal pela Uniasselvi. Mestre em Segurança Pública, Cidadania e Direitos Humanos pela Universidade do Estado do Amazonas (UEA).

\section{SOLANA NUNES VIEIRA}

Bacharel em Enfermagem pela Universidade do Estado do Amazonas. Especialista em Unidade de Terapia Intensiva.

\section{LEONARDO NAVES DOS REIS}

Professor e coordenador do Programa de Pós-graduação em Segurança Pública, Cidadania e Direitos Humanos da Universidade do Estado do Amazonas. Doutor e Mestre pelo Programa de pós-graduação do Departamento de Enfermagem Psiquiátrica e Ciências Humanas da Escola de Enfermagem de Ribeirão Preto da USP.

\section{RESUMO}

A reflexão da sociologia sobre diversos fenômenos traz contribuições importantes para esclarecer comportamentos estabelecidos socialmente que possam provocar ou consolidar certos problemas, como a violência de gênero. Este artigo é uma revisão crítica da literatura do campo da sociologia, na qual se destaca a contribuição do sociólogo francês Pierre Bourdieu sobre a violência simbólica abordada na obra A dominação masculina, de 1995. Por meio dessa reflexão pode-se notar que o aumento da violência contra a mulher que o país vivencia, apesar de suas leis abrangentes, é um possível fruto de heranças culturais estruturadas nas bases das instituições sociais. Isso se reflete de maneira implícita nos serviços de enfrentamento à violência doméstica.

Palavras-chaves: Violência doméstica; Violência contra a mulher.

\section{ABSTRACT}

\section{THE CHALLENGES OF COMBATING VIOLENCE AGAINST WOMEN UNDER THE VIEW OF PIERRE BOURDIEU}

The reflection of sociology about various phenomena brings important contributions to clarify socially established behaviors that can provoke or consolidate certain problems, such as gender violence. This article is a critical review of the literature in the field of sociology, based on the work of the French sociologist Pierre Bourdieu on symbolic violence, The male domination, of 1995. Through this reflection it can be noted that the increase in violence against women that the country experiences, despite its comprehensive laws, is a possible result of cultural inheritances structured based on social institutions. This is reflected in an implicit way in services to combat domestic violence.

Keywords: Domestic violence; Violence against women. 


\section{INTRODUÇÃO}

Pierre Bourdieu, ao longo de sua trajetória como pesquisador, fez várias contribuições no campo da sociologia, apesar de ter sido filósofo por formação (CHARTIER; LOPES, 2002). A dominação e a violência simbólica foram alguns dos assuntos abordados, além de pensamentos críticos sobre a política, o capital cultural, a educação e outros (CHARTIER; LOPES, 2002). Em sua obra A dominação masculina, de 1995, ao tratar da violência simbólica demonstra como comportamentos implícitos ou quase consolidados socialmente contribuem para a diferenciação de gênero, que por sua vez implicaria um grupo dominado pelo "masculino" (BOURDIEU, 2010).

Outros pensamentos sobre poder e dominação aplicam-se às relações de gênero, em que o homem é detentor de poderes e privilégios sociais sobre a mulher, e assim, de acordo com cada organização social, as desigualdades de gênero podem exercer maior poder do que em outras (OMS, 2010). Foucault (1988) compreende que o exercício do poder se dá a partir de pontos variados, móveis e de relações de desigualdade.

No Brasil, a luta pela erradicação da violência doméstica contra a mulher começou com as reivindicações do movimento feminista na década de 1970, que até hoje exerce uma grande influência para as mudanças sociais e contribui para a diminuição das desigualdades entre homens e mulheres. A criação do Conselho Nacional dos Direitos da Mulher (CNDM) em 1984 foi uma das vitórias do movimento feminista. Logo após, houve a promulgação da Constituição Federal com garantias de leis específicas de amparo à mulher. Finalmente, em 2006 se deu a sanção da Lei n 11.340, de 2006, que visa coibir a violência doméstica e familiar contra a mulher no Brasil (PINTO, 2010).

Apesar dos meios legais e políticos para frear o avanço da violência doméstica, no período entre 2007 e 2017 foi registrado um aumento na taxa de homicídios de mulheres de 20,7\%, assim a taxa passou de 3,9 assassinatos por 100 mil mulheres para 4,7 por 100 mil mulheres (INSTITUTO DE PESQUISA ECONÔMICA APLICADA; FÓRUM BRASILEIRO DE SEGURANÇA PÚBLICA, 2019). Cabe uma reflexão relacionada às mulheres que foram vítimas fatais da violência. Estas, por vezes, podem ter vivenciado outras situações antecedentes ao desfecho fatal, como agressão física, psicológica, sexual e outras, ou estarem inseridas em um ciclo de violência, ou seja, o feminicídio poderia ter sido evitado se essas mulheres tivessem tido possibilidades e amparo concretos para sair do ciclo de violência (INSTITUTO DE PESQUISA ECONÔMICA APLICADA; FÓRUM BRASILEIRO DE SEGURANÇA PÚBLICA, 2018)

Apesar de todo o esforço empenhado no enfrentamento da violência contra a mulher e de todo o aparato legal, as estimativas ainda são alarmantes, necessitando de explicações aprofundadas e críticas que deem luz a um problema que parece perdurar.

Por todo o exposto, questiona-se quais os símbolos de dominação predominantes na sociedade contemporânea e como podem vir a contribuir para o aumento da violência doméstica contra a mulher no Brasil. Nesse contexto, este estudo tem por objetivos: contextualizar, à luz do pensamento de Pierre Bourdieu, a relação entre violência simbólica e o aumento da violência doméstica contra a mulher, no Brasil; refletir sobre como as estruturas de pensamento podem estar relacionadas à ineficácia de políticas, programas e leis que vigoram nos dias atuais. 


\section{METODOLOGIA}

Trata-se de uma revisão crítica da literatura do campo da sociologia, com destaque para a contribuição crítica do sociólogo francês Pierre Bourdieu sobre a violência simbólica abordada na obra A dominação masculina, de 1995, contextualizando-se a violência doméstica contra a mulher no Brasil dos dias atuais.

A escolha da obra de Pierre Bourdieu foi motivada pela percepção diferenciada que este sociólogo trouxe no final do século XX, relacionando a estrutura de pensamentos estabelecidos socialmente à legitimação de atitudes que podem sugerir uma desigualdade social organizada, ainda que implícita, ou como denominada por Bourdieu, simbólica. Este pesquisador desenvolveu um estudo na população da Cabília, região do mediterrâneo, onde, segundo ele, os berberes conservam os paradigmas voltados ao falo narcisista e androcêntrico, características encontradas nos demais povos do mediterrâneo (BOURDIEU, 2010).

\section{A ESTRUTURAÇÃO SOCIAL E A VIOLÊNCIA SIMBÓLICA}

Antes de conceituar violência simbólica é necessária a compreensão do pensamento bourdieusiano sobre como a sociedade é estruturada e como as ações do sujeito individual são selecionadas no âmbito coletivo. Para Bourdieu, o habitus é o elo entre o sujeito individual e suas subjetividades com a sociedade em sua totalidade. Esse elo funciona como uma estrutura estruturante. Em outras palavras, são práticas sociais construídas a partir de "um sistema de disposições duráveis e transponíveis" (BOURDIEU, 1983, p. 65) e que funcionam de acordo com o meio social do sujeito, integrando sua compreensão de mundo à suas ações (BOURDIEU, 1983).

No campo pratica-se o habitus, este indica a posição social que o sujeito ocupa e as ações do sujeito individual tornam-se intrinsicamente estruturadas no campo. Dessa forma, cada organização social terá suas regras e, dentro dessa estrutura social, cada indivíduo fará a escolha de suas ações com base nas relações de poder, hierarquias e regras estabelecidas no campo (CORCUFF, 1993).

Logo, as ações são influenciadas pela posição social do sujeito que a produz, tendo em vista a estruturação das camadas sociais nas quais se insere. Apesar de cada pessoa ser influenciada pela sua própria subjetividade, suas ações já estão sendo previamente estruturadas, ou seja, o sistema simbólico está relacionado com comportamentos sociais estruturados de acordo com as classes dominantes, a divisão do trabalho e o gênero. Sendo assim, as ações dos indivíduos ou o habitus também se enquadram dentro do papel social que estes desempenham (CORCUFF, 1993).

Рara Bourdieu, a violência simbólica caracteriza-se como comportamentos quase imperceptíveis para a própria vítima, entretanto, isso não a torna "fantasiosa" ou "irreal", ela está inserida em estruturas sociais com bases solidificadas (BOURDIEU, 2010). Os símbolos da dominação por vezes são reforçados em esferas do Estado, na escola, pela Igreja e na família, facilitando a naturalização de comportamentos de dominação (BOURDIEU, 2010).

Quando Pierre Bourdieu traz a ideia do poder simbólico, ele afirma a necessidade da cumplicidade entre o sujeito que exerce a dominação com aquele que se submete a ela. Afinal, a estrutura de poder impõe que ambos os lados se comportem segundo ordens estabelecidas, ou, resumidamente, dominados pela própria dominação" (BOURDIEU, 2010). 


\section{A DOMINAÇÃO MASCULINA SOB A ÓTICA DE BOURDIEU}

Na obra A dominação masculina, o autor retrata os costumes vividos na região da Cabília e observa a forte influência da dicotomia e do modelo androcêntrico nas relações de gênero, assim, o feminino e o masculino são vistos como opostos e representados por vezes pela anatomia e por fenômenos e elementos da natureza. O feminino seria o inferior, sensível, frio, escuro, úmido, enquanto o masculino seria representado pelo superior, racional, quente, claro e seco. Os órgãos sexuais também possuem significados quanto a sua forma, pois a ereção remete a algo superior, enquanto a vagina possui a simbologia do órgão invertido, retomando a percepção dicotômica de que enquanto um deflora, é ereto e tem sentido fora-dentro, o outro é invertido, nulo e possui sentido dentro-fora (BOURDIEU, 2010).

Quando Aristóteles afirma que o macho possui natureza superior à da fêmea, sendo o único portador da "semente" da reprodução, e estende tais ideias para a raça humana, tende-se à aceitação da supremacia masculina por parte da sociedade (LOPES, 2010) e esses símbolos de dominação são incorporados de maneira "inconsciente" na relação social, de modo a se tornarem quase imperceptíveis (BOURDIEU, 2010).

Outro símbolo da dominação, observado por Bourdieu, é a divisão do trabalho, segundo a qual o homem exerce funções nobres e de valores reconhecidos socialmente, enquanto a mulher realiza trabalhos considerados humildes e em lugares restritos como o lar, o vilarejo, a lavoura, cuidando dos animais, do leite, dos filhos. Outro ponto abordado foram as manifestações físicas provocadas por emoções que as mulheres apresentavam como humilhação, culpa, vergonha, timidez e outras, como respeito e admiração pelo parceiro (BOURDIEU, 2010).

É assim que a jovem cabila interiorizava os princípios fundamentais da arte de viver feminina, de boa conduta, inseparavelmente corporal e moral, aprendendo a vestir e a usar diferentes vestimentas que correspondem a seus diferentes estados sucessivos de menina, virgem núbil, esposa, mãe de família, e, adquirindo insensivelmente, tanto por mimetismo inconsciente quanto por obediência expressa, a maneira correta de amarrar sua cintura ou seus cabelos, de mover ou manter imóvel tal ou qual parte do seu corpo ao caminhar, de mostrar o rosto e de dirigir o olhar (BOURDIEU, 2010, p. 37).

Observa-se a capacidade criativa que a indústria voltada ao público feminino possui em despertar o desejo de consumo oferecendo produtos que ditam a moda, a beleza e a padronização dos corpos e atribuem valores sociais aos bens de consumo. Isso acontece independentemente do gênero, porém, o público feminino é mais facilmente seduzido por propagandas anti-idade, cirurgias plásticas, boas maneiras e costumes (NOVAES; VILHENA, 2003).

Além disso, apesar de a mulher estar ganhando cada vez mais espaço no mercado de trabalho e nas universidades, ainda é notável o contingente masculino dominante nos mais altos cargos hierárquicos dentro das instituições de ensino, no setor de saúde, nas empresas, na política e nas igrejas, mesmo que o principal público seja formado pelo gênero feminino (ABRAHÃO; VIEL, 2018). Ainda que a violência atinja predominantemente mulheres em condições sociais mais baixas (TEIXEIRA et al., 2015), a estrutura de dominação do feminino está presente até mesmo em situações consideradas comuns (BOURDIEU, 2010).

Pierre Bourdieu cita a preferência quase totalitária das mulheres francesas por um homem mais alto e com maior idade em comparação a ela própria e a rejeição de uma parte delas por homens com características 
invertidas a essas. Estes símbolos são observados como a percepção da mulher de diminuição por estar ao lado de um homem menor que ela, ou a inversão dos papéis sociais. Culturalmente, o patriarcalismo traz a ideia do homem provedor e essa relação com a altura é vista por Bourdieu como uma escolha que possa garantir maturidade e segurança no relacionamento (BOURDIEU, 2010).

A dominação "parece apoiar-se na força bruta, das armas ou do dinheiro" (BOURDIEU, 2010, p. 53), no entanto, a inclinação ou pré-disposição à subordinação é vista como um estado de conhecimento que induz o sujeito à inércia, porém, esse conhecimento da dominação não se caracteriza como algo "consciente" e sim perpetuado em estruturas sociais ao longo dos anos (BOURDIEU, 2010).

\section{O ENFRENTAMENTO À VIOLÊNCIA DOMÉSTICA NO BRASIL}

A violência contra a mulher, como mencionado anteriormente, é um grave problema em determinadas sociedades, como no Brasil, que ainda possui índices crescentes e onde tais estatísticas podem ter influências diretas do contexto cultura. O tema foi levantado pelo movimento feminista durante a ditadura militar e, graças a isto, uma série de denúncias sobre a violência perpetrada no âmbito doméstico chegou ao conhecimento da sociedade, já num estágio crítico (BANDEIRA, 2014).

O sancionamento da Lei n 11.340, conhecida como Lei Maria da Penha, ocorreu somente em 2006, logo após a condenação do Estado brasileiro pela Comissão Interamericana dos Direitos Humanos, da Organização dos Estados Americanos, por negligência e omissão no caso de Maria da Penha Maia Fernandes, brasileira, vítima de violência doméstica. Esta lei visa coibir e prevenir a violência doméstica e familiar contra a mulher de forma ampla, caracterizada por qualquer ato que cause dano físico, psicológico, moral, patrimonial ou sexual fundamentado no gênero (BRASIL, 2006). O artigo $5^{\circ}$ configura o agressor como qualquer indivíduo que inflija tais danos a mulher com quem mantenha convívio domiciliar, vínculo afetivo independentemente de coabitação ou relação familiar. A lei coloca a necessidade de varas especializadas no combate à violência doméstica e delegacias de atendimento à mulher, com disponibilidade de equipe multidisciplinar e medidas protetivas de urgência (BRASIL, 2006).

Essa lei foi fundamental para a definição de violência doméstica, proporcionando pesquisas mais específicas e que demonstrassem a desnaturalização dos crimes no âmbito familiar. Foram muitas décadas até que ela passasse a vigorar, defendendo o direito da mulher a uma vida sem violência. Por vezes, ideologias machistas presentes no Direito induziam a interpretações que reforçavam a dominação masculina nos crimes de violência doméstica (CASTRO; SILVA, 2017; CORRÊA, 1983). Um exemplo disso é o crime de estupro pelo cônjuge, cuja legitimação era discutida até a década de 1970 (CASTRO; SILVA 2017), e ainda, o homicídio da mulher nos casos de adultério, nos quais a pena era amenizada por razão de ser exercida em favor da legítima defesa da honra (CORRÊA, 1983). Bourdieu afirma que "a estrutura deste sistema simbólico, que é em si o sistema jurídico, cumpre ainda uma função política de instrumento de imposição ou de legitimação da dominação de uma classe sobre a outra" (BOURDIEU apud GONZAGA, 2016, p. 9).

Atualmente, um estudo disponibilizado pelo Conselho Nacional de Justiça (CNJ) sobre a aplicação da Lei Maria da Penha demonstrou a morosidade do sistema judiciário na resolução dos casos, com aumento de medidas protetivas, de novos casos, de casos pendentes e de feminicídios, no período entre 2016 e 2017 (CONSELHO NACIONAL DE JUSTIÇA, 2018). 
Em todos esses anos de lutas, não somente contra a violência, mas também contra um sistema jurídico historicamente formado com predominância de indivíduos do gênero masculino (ABRAHÃO; VIEL, 2018), tornase evidente, do ponto de vista das estruturas sociais simbólicas, que é necessário muito esforço para romper paradigmas. A efetivação dessas mudanças tem como pré-requisito o despertar de consciência de uma parcela majoritária da população, a fim de exercer influência social e política. Portanto, romper com o esquema social é ir além de intervir somente na vida do sujeito que sofre violência física. É necessário libertar o indivíduo de um sistema que vem sendo alimentado muito antes da sua própria existência e que possui raízes profundas (BOURDIEU, 2010).

\section{A DENÚNCIA CONTRA A VIOLÊNCIA DOMÉSTICA}

Apesar de todo o aparato legal que a mulher possui nos casos de violência doméstica, a violência simbólica também pode ocorrer quando um indivíduo está inserido em um contexto de classes sociais mais baixas (VASCONCELOS, 2002) e, assim, mulheres com baixo nível escolar, econômico ou em situação de vulnerabilidade social podem ser submetidas a situações de humilhação, vergonha e culpa por estarem inseridas em um sistema de poderes e hierarquias. No contexto da violência doméstica, a mulher sofre uma pré-condenação social por "permitir" a violência e permanecer no relacionamento, sendo culpada por incitar ou provocar o agressor (BANDEIRA, 2008). Esses são somente alguns exemplos, porém, mesmo o profissional que atua nos serviços de proteção à mulher pode corroborar essas ideias estruturadas socialmente e praticar a violência simbólica institucionalizada no mau atendimento.

As mulheres em situação de violência doméstica tendem a procurar tardiamente um serviço de proteção e segurança, e o principal motivo para isso é o medo do agressor, assim como das possíveis consequências da denúncia à vida de todos os atores envolvidos no contexto de violência: filhos, agressor e a vítima (CAMPOS, 2017; SENADO FEDERAL, 2017). Logo, na maioria das vezes em que uma mulher se dispõe a prestar queixa, é um caso de risco iminente de morte, ameaças à mulher, a familiares ou aos filhos, na tentativa da mulher de interromper o ciclo de dominação daquele relacionamento. Além disso, em sua maioria, as mulheres encontram-se em condições sociais desfavoráveis, de dependência financeira, com desemprego e baixa escolaridade, situações em que o agressor acaba sendo o principal mantenedor do lar (MENEZES, 2000 apud CASTRO; SILVA, 2017).

Não obstante a promulgação da Lei Maria da Penha, ainda é notável o despreparo dos profissionais de segurança pública no que tange ao atendimento a essas mulheres. Os profissionais se cingem à mentalidade de apenas prender o possível agressor, sem ponderar outras questões, atropelando até mesmo garantias constitucionais, trazendo consequências irreparáveis às partes (PASINATO, 2016).

No Mato Grosso, uma pesquisa realizada com policiais militares para identificar se os atendimentos de violência doméstica contra mulher eram tratados de forma diferenciada por policiais do sexo feminino em comparação com policiais do sexo masculino, verificou-se que tais casos não são caracterizados como ocorrências de grande importância, por serem um crime evitável, na concepção de alguns profissionais. Entre as policiais do sexo feminino, $82 \%$ entendem que todas as formas de violência devem ser registradas, enquanto 33\% dos homens veem necessidade de registrar somente a violência física e $27 \%$, a violência física e psicológica (MARTINS; BERTOLINE, 2013).

Da mesma maneira, percepções similares são identificadas dentro das delegacias de atendimento à mulher (LINS, 2017) e por todo o percurso do processo, dificultando o vínculo de confiança entre a população em situação de violência doméstica e o serviço policial. Nesse mesmo cenário, a ocorrência de violência 
psicológica muitas vezes é negligenciada e quando há ameaça de morte, as providências cabíveis não são tomadas, sob diversas alegações (ABDALA; SILVEIRA; MINAYO, 2011), tornando esse serviço pouco eficaz na concepção de muitas brasileiras (SENADO, 2017).

Em uma Delegacia Especializada de Atendimento à Mulher (DEAM), Lins (2017) observou nas falas de policiais civis que estes lamentam por não terem recebido treinamento adequado para atuar na DEAM, e que o processo de aprendizagem é concretizado na prática de erros e acertos.

Pasinato (2015, p. 409) afirma que "as mulheres no Brasil ainda enfrentam um déficit em termos de reconhecimento social do seu pleno direito à justiça e que interfere com as práticas discriminatórias que prevalecem nas instituições policiais e judiciais.

\section{CONCLUSÃO}

Infelizmente, o Brasil ainda é um país que possui uma cultura machista e o preconceito está inserido não somente nos homens, mas nas próprias mulheres. A estrutura de pensamento parte do núcleo familiar e se estende para instituições com influências ainda maiores. Assim, o aumento da violência contra a mulher que o país vivencia é fruto de heranças culturais. Bourdieu, quando discute a submissão "consciente", também ressalta a reponsabilidade do opressor e cita que o habitus é transponivel e o sujeito social não perde suas subjetividades. Essa perspectiva social menos preconceituosa é um ponto de partida para grandes mudanças nos índices de violência doméstica, que surtirá efeito somente com o comprometimento dos profissionais que atuam nos órgãos competentes, o empenho dos Poderes do Estado e de uma população esclarecida.

Portanto, são necessárias políticas voltadas para a educação, não somente das mulheres que se encontram em situação de violência, mas também de toda a sociedade, desde o público infantil. Essa mobilização, mesmo que a longo prazo, poderia trazer uma mudança significativa nos alicerces culturais da sociedade. Quanto ao trâmite dos casos processuais, o sistema judiciário, assim como os demais serviços de apoio à mulher, ainda traz vestígios do machismo, que infelizmente está relacionado à formação profissional do sujeito e também com a maneira de organização do serviço. Por fim, a mulher, mesmo com todo avanço social em busca da igualdade de gênero, ainda é vítima não somente da violência doméstica, mas de um conjunto de ideias sociais que tende a torná-la inferior ao homem e somente com um posicionamento coerente de toda a sociedade os índices de violência poderão diminuir.

\section{REFERÊNCIAS BIBLIOGRÁFICAS}

ABDALA, Cláudia; SILVEIRA, Kátia; MINAYO, Maria Cecília de Souza. Aplicação da Lei Maria da Penha nas delegacias de mulheres: O caso do Rio de Janeiro. DILEMAS: Revista de Estudos de Conflito e Controle Social, v. 4, n. 4, p. 571-600, nov.-dez. 2011.

ABRAHÃO, Jéssica; VIEL, Paula. O Espectro da Masculinização das Mulheres e os Desafios da Desigualdade de Gênero Em Posições de Poder1. In: Intercom-Sociedade Brasileira de Estudos Interdisciplinares da Comunicação, $41^{\circ}$ Congresso Brasileiro de Ciências da Comunicação. 2018.

BANDEIRA, Lourdes. Três décadas de resistência feminista contra o sexismo e a violência feminina no Brasil. Sociedade e Estado, v. 24, n. 2, p. 401-148, 2008. 
BANDEIRA, Lourdes Maria. Violência de gênero: a construção de um campo teórico e de investigação. Sociedade Estado, v. 29, n. 2, p. 449-469, maio-ago. 2014.

BOURDIEU, Pierre. Sociologia. Tradução de Renato Ortiz. São Paulo: Ática, 1983.

BOURDIEU, Pierre. A dominação masculina. Tradução de Maria Helena Kuhner. 9. ed. Rio de Janeiro: Bertrand Brasil, 2010.

BRASIL. Diário Oficial da União. Lei n 11.340, de 7 de agosto de 2006. Brasília, DF: Presidência da República, 2006.

CAMPOS, Carmen Hein de. Lei Maria da Penha: necessidade de um novo giro paradigmático. Revista Brasileira de Segurança Pública, v. 11, n. 1, p. 10-22, fev.-mar. 2017.

CASTRO, Bruno Denis Vale; SILVA, Artenira da Silva e. Atuação da Autoridade Policial e do Poder Judiciário no Combate à Violência Doméstica Contra a Mulher na Cidade de São Luís/MA. Revista Opinião. Jurídica, v. 20, p. 59-83, jan.-jun. 2017.

CHARTIER, Roger; LOPES, José Sérgio Leite. Pierre Bourdieu e a história. Topoi, p. 139-182, mar. 2002.

CONSELHO NACIONAL DE JUSTIÇA. O Poder Judiciário na aplicação da Lei Maria da Penha. Brasília: CNJ, 2018. Disponível em: < https://www.cnj.jus.br/wp-content/ uploads/2018/06/5514b0debfb866190c20610890849e10_1c3f3d621da010274f3d69e6a6d6b7e6. $p d f>$. Acesso em: 10/03/2019.

BOURDIEU, Pierre; WACQUANT, Loïc J. D. Réponses. Pour une anthropologie reflexive. Paris: Le Seuil, 1992. Resenha de: CORCUFF, Philippe. Revue française de sociologie, v. 34, n. 2, p. 293-296, 1993.

CORRÊA, Marisa. Morte em Família: representações jurídicas de papéis sexuais. Rio de Janeiro: Edições Graal, 1983.

FOUCAULT, Michel. História da Sexualidade: A Vontade de Saber. Tradução de Maria Thereza da Costa Albuquerque e J. A. Guilhon Albuquerque. Rio de Janeiro: Graal, 1988.

GONZAGA, Alexandre Luís. Mudança Social e Resistência: O machismo como ideologia do discurso jurídico. Interletras, v. 22, n. 4, p. 1-16, out. 2015-mar. 2016.

INSTITUTO DE PESQUISA ECONÔMICA APLICADA; FÓRUM BRASILEIRO DE SEGURANÇA PÚBLICA. Atlas da Violência 2018 Ipea e FBSP. São Paulo: Ipea; FBSP, jun. 2018.

INSTITUTO DE PESQUISA ECONÔMICA APLICADA; FÓRUM BRASILEIRO DE SEGURANÇA PÚBLICA. Atlas da Violência 2019 Ipea e FBSP. São Paulo: Ipea; FBSP, jun. 2019.

LINS, Beatriz Accioly. "Não existe policial de DDM, existe policial": escolhas, empatia e militância em estudos sobre violência contra mulheres entre policiais de Delegacias de Defesa da Mulher". Revista Brasileira de Segurança Pública, v. 11, n. 2, p. 88-104, ago.-set. 2017.

LOPES, Marisa. Para a história conceitual da discriminação da mulher. Cadernos de Filosofia Alemã, n. 15, p. 81-96, jan.-jun. 2010.

MARTINS, Emirella Perpétua Souza; BERTOLINE, Vera Lúcia. Violência contra mulher: diferenças e semelhanças no atendimento policial militar, na perspectiva de gênero. RMH, v. 10, p. 52-65, jan.-jun. 2013.

NOVAES, Joana; de VILHENA, Junia. De Cinderela a moura torta: sobre a relação mulher, beleza e feiúra. Interações, v. 8, n. 15, p. 9-36, jun. 2003. 
Os desafios do combate à violência contra a mulher sob a ótica de Pierre Bourdieu

Brenda Alice Andrade Vidigal, Marcos Prata Bentes,

Solana Nunes Vieira e Leonardo Naves dos Reis

OMS. Prevenção da violência sexual e da violência pelo parceiro íntimo contra a mulher: ação e produção de evidência. OMS: Genebra, 2010.

PASINATO, Wânia. Acesso à justiça e violência doméstica e familiar contra as mulheres: as percepções dos operadores jurídicos e os limites para a aplicação da Lei Maria da Penha. Revista Direito GV, v. 11, n. 2, p. 407-428, 2015.

PASINATO, Wânia; ONU MULHERES; SECRETARIA DE POLÍTICA PARA AS MULHERES; SECRETARIA NACIONAL DE SEGURANÇA PÚBLICA. Diretrizes nacionais Feminicídio. Investigar, processar e julgar com a perspectiva de gênero as mortes violentas de mulheres. Brasília, DF: ONU Mulheres; SPM, Senasp, abr. 2016.

PINTO, Célia Regina Jardim. Feminismo História e Poder. Revista Sociologia Política, v. 18, n. 36, p. 15-23, 2010.

SENADO FEDERAL. Violência doméstica e familiar contra mulher. 7. ed. Brasília, DF: Senado Federal, 2017.

TEIXEIRA, Selma Villas Boas; MOURA, Maria Aparecida Vasconcelos; SILVA, Leila Rangel da; QUEIROZ, Ana Beatriz Azevedo; SOUZA, Kleyde Ventura de Souza; NETTO, Leônidas Albuquerque. Violência perpetrada por parceiro íntimo à gestante: o ambiente à luz da teoria de Levine. Revista Escola de Enfermagem da USP, v. 49, n. 6, p. 882-889, 2015.

VASCONCELOS, Maria Drosila. Pierre Bourdieu: a herança sociológica. Educação \& Sociedade, v. 23, n. 78, p. 77-87, abr. 2002. 

sob a ótica de Pierre Bourdieu

Brenda Alice Andrade Vidigal, Marcos Prata Bentes, Solana Nunes Vieira e Leonardo Naves dos Reis

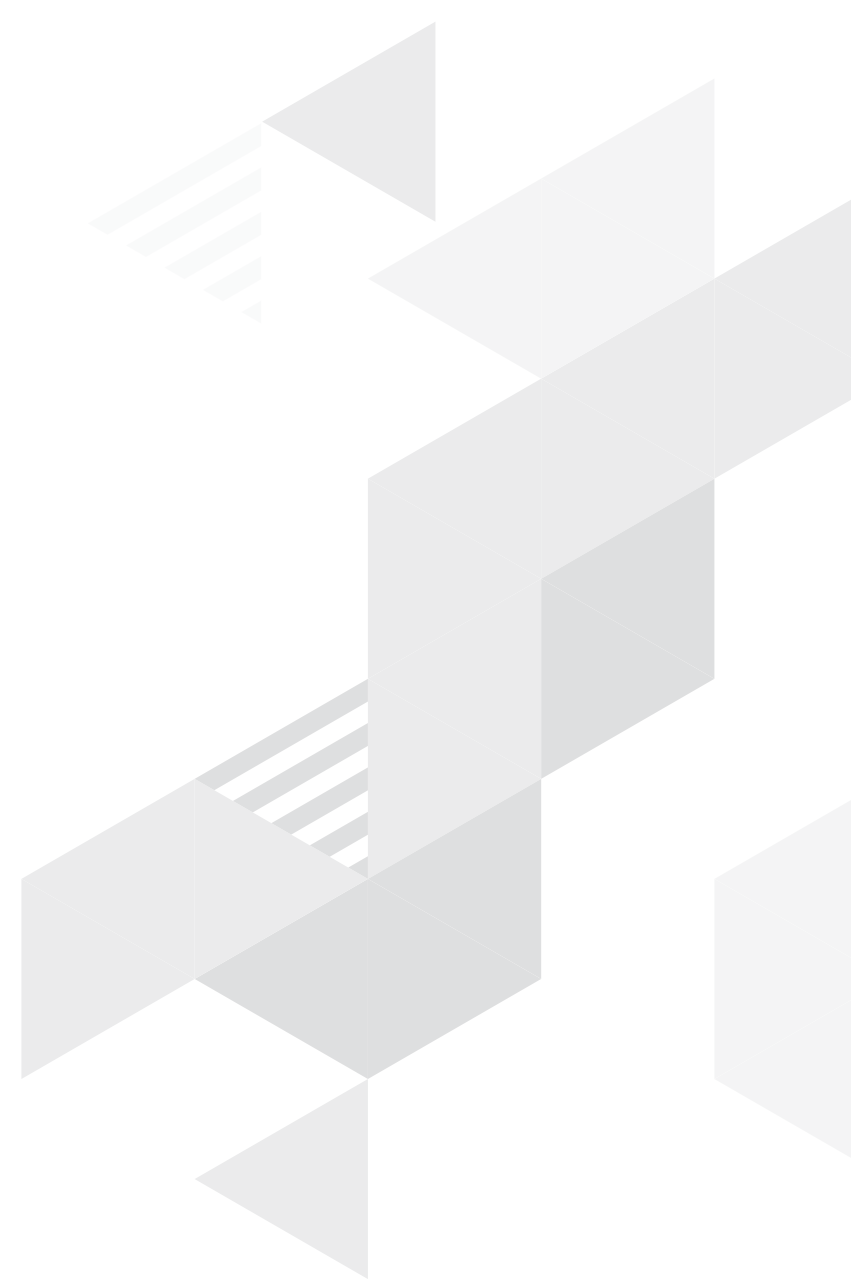

